\title{
Grey Spectrum Analysis of Air Quality Index and Housing Price in Handan
}

\author{
Kai Zhang, Yan Chen (D, and Lifeng Wu (iD) \\ College of Management Engineering and Business, Hebei University of Engineering, Handan 056038, China \\ Correspondence should be addressed to Yan Chen; 964129856@qq.com
}

Received 7 August 2019; Accepted 18 September 2019; Published 25 November 2019

Guest Editor: Francesco Tajani

Copyright (c) 2019 Kai Zhang et al. This is an open access article distributed under the Creative Commons Attribution License, which permits unrestricted use, distribution, and reproduction in any medium, provided the original work is properly cited.

To analyze the relationship between air quality index (AQI) and housing price, six relationship indexes between air quality index and housing price were calculated using grey spectrum theory, specifically grey association spectrum, grey cospectrum, grey amplitude spectrum, grey phase spectrum, grey lag time length, and grey condense spectrum. Three main change periods were extracted. There was a negative correction between the air quality and the housing price in Handan. The results provide a basis for the government's measures to prevent haze.

\section{Introduction}

The real estate industry drives the economy. The added value of real estate and related industries accounts for $15.8 \%$ of China's gross domestic product (GDP), the share of real estate in GDP is 3\% in America, and the data for Japan are $11 \%$. Beijing-Tianjin-Hebei, the Yangtze River Delta, the Pearl River Delta, Chengdu-Chongqing, and the middle reaches of the Yangtze River are China's five largest city clusters. Their $11 \%$ land area contributes $55 \%$ to the economy and $47 \%$ to commercial housing sales (Boao $21^{\text {st }}$ Century Real Estate Forum $19^{\text {th }}$ Annual Conference). Research on housing price has been performed. Housing prices have been driven by land price and have had a strong effect on land price [1]. The increase in population is expected to reduce the land area per capita, resulting in the rise of housing price [2]. There are commercial housing and social housing in China, and commercial housing has been the focus of most research works [3]. High housing price will cause social conflicts, and the Chinese government has launched a series of measures to limit housing price [4]. For the government to formulate more accurate measures of housing price, a long short-term memory approach is proposed to predict the housing price [5].

In addition to creating a lot of jobs, economic development has also created a lot of problems, such as air pollution.
Handan, a city in southern Hebei Province, is shown in Figure 1. Gross domestic product and total construction output showed the same trend from 2015 to 2018 (Figure 2). Economic growth slowed in 2017 as the country adjusted its industrial structure. The development of the construction industry has raised the housing price and brought about the problem of environmental pollution. AQI in Handan from 2014 to 2018 is shown in Figure 3. As shown, polluted months were more than that of good months. Air pollution reduces the quality of human environment.

Air pollution is still a major problem faced by the world today. Air quality is affected by a variety of factors. Many scholars have performed research on air quality, including studies on the influence of tree species on air quality improvement [6]. Despite this, it is generally agreed that human socioeconomic activities have the greatest impact on the environment $[7,8]$. Air quality problems are common in China, and haze is not evenly distributed: the developed eastern regions face more serious air quality problems than western regions [9]. Under the Chinese government's strict emission measures, air quality has improved greatly [10]. Analysis of factors related to air pollution is the key to haze control. The relationship between outdoor air pollution and sick building syndrome symptoms is researched [11]. The problem of air pollution has been taken seriously in recent years in China, and equipment to measure air quality have 


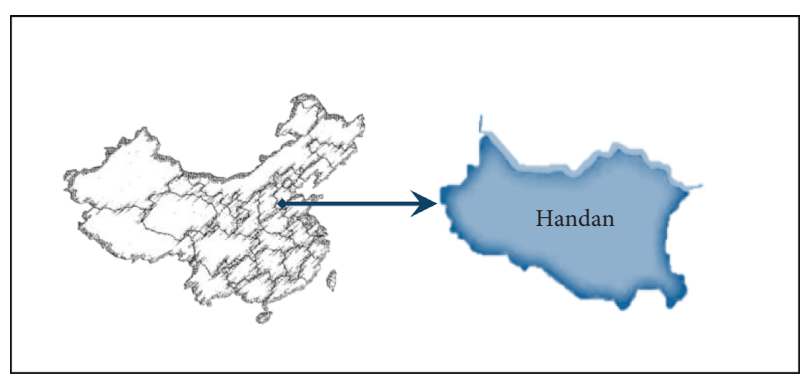

FIgURE 1: Location of Handan in Hebei Province.

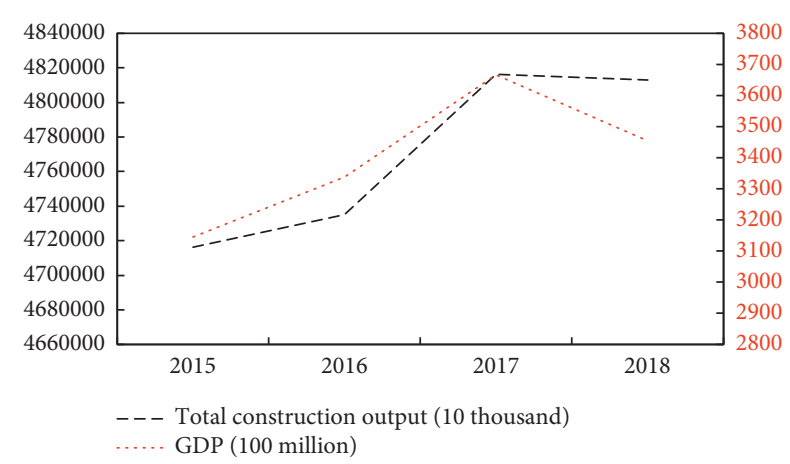

Figure 2: Total construction output and gross domestic product (GDP) from 2015 to 2018 in Handan.
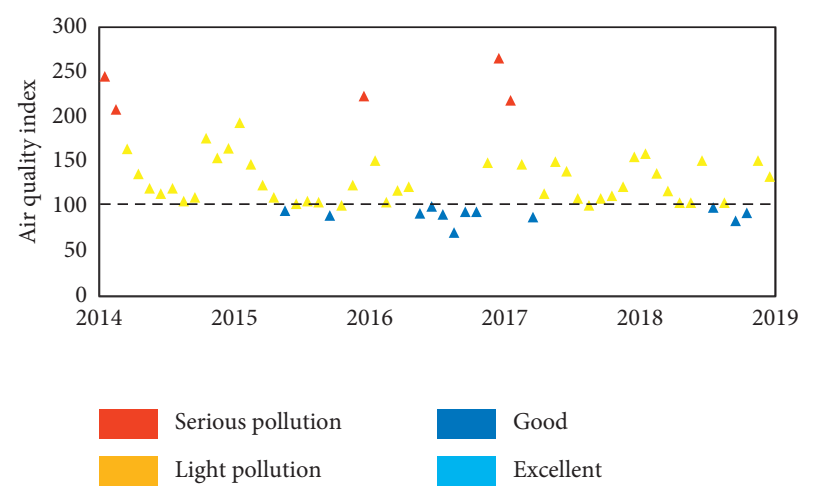

Figure 3: Air quality index (AQI) in Handan from 2014 to 2018.

been installed in many cities. Air quality data are incomplete. Grey system theory can address the small sample sizes and poor quality of data [12]. Scholars have performed further research projects. The traditional grey model has been used to provide particulate matter information for the roadside inhabitants [13]. The grey model with fractional order accumulation has been used to predict air quality [14], and grey relational analysis has been used to determine whether carbon price has multiple timescales [15].

The purpose of this study is to assess the relationship between AQI and housing price. The mechanism by which air quality affects housing price has been studied, and suggestions for government programs are provided here.

The paper has the following structure. The calculation process of grey spectrum theory is presented in Section 2. The grey spectrum theory used in real-world cases is presented in Section 3. The paper is summarized in Section 4.

\section{Method}

The degree of correlation in grey relational analysis was here substituted for the correlation number in spectrum analysis, and then grey association spectrum, grey cospectrum, grey condense spectrum, grey phase spectrum, grey lag time length, and other indicators were found $[16,17]$. Results are shown in Figure 4. The grey spectrum algorithm is presented below.

Step 1. Standardization:

$X_{i}=\left\{X_{i}(t), t=1,2, \ldots, m ; i=1,2\right\}$ is the discrete time series ( $m$ represents the sample size and $i$ is the sequence name). To make each sequence comparable, $X_{i}$ is standardized. The results are as follows:

$$
\begin{aligned}
& d_{i}=\frac{1}{m-1} \sum_{t}^{m-1}\left|X_{i}(t+1)-X_{i}\right|, \quad t=1,2, \ldots, m-1, \\
& y_{i}=\left\{\frac{X_{i}(t)}{d_{i}}, \quad t=1,2, \ldots, m\right\} .
\end{aligned}
$$

Step 2. The increment sequence is defined as follows:

$$
\Delta y_{i}=\left\{\Delta y_{i}(t)=y_{i}(t+1)-y_{i}(t), \quad t=1,2, \ldots, m-1\right\} .
$$

Step 3. The correlation coefficient of each time period:

$$
\rho_{12}= \begin{cases}\operatorname{sgn}\left(\Delta y_{1}(t) \Delta y_{2}(t+\tau)\right), & \frac{\min \left(\left|\Delta y_{1}(t)\right|,\left|\Delta y_{2}(t+\tau)\right|\right)}{\max \left(\left|\Delta y_{1}(t)\right|,\left|\Delta y_{2}(t+\tau)\right|\right)} \\ 0, & \left(\Delta y_{1}(t) \Delta y_{2}(t+\tau)=0\right),\end{cases}
$$

where $\operatorname{sgn}\left(\Delta y_{1} \Delta y_{2}(t+\tau)\right)=\left\{\begin{array}{l}1\left(\Delta y_{1} \Delta y_{2}(t+\tau)>0\right) \\ 0\left(\Delta y_{1} \Delta y_{2}(t+\tau)=0\right) ; \Delta y_{1} \\ -1\left(\Delta y_{1} \Delta y_{2}(t+\tau)<0\right)\end{array}\right.$ is the controlled sequence of $\Delta y_{2}, \Delta y_{2}$ is calculated in the same way as $\Delta y_{1}$; and $\tau$ is the time difference factor.

Step 4. The correlation coefficient is defined as follows:

$$
r_{12}(\tau)=\frac{1}{m-\tau} \sum_{t=1}^{m-\tau-1} \rho_{12}(t), \quad \tau=0,1,2, \ldots, \Delta .
$$

The order of the model is represented by $\Delta$. On the basis of experience, $\Delta$ is taken as $1 / 10 \sim 1 / 3$ of the sequence length [18].

Step 5. Grey association spectrum and grey cospectrum are calculated. According to spectral theory and equation (4), the across spectrum is decomposed into real and imaginary parts. Real parts are represented by $P_{12}(k)$, and the latter is represented by $Q_{12}(k)$. The sequence changes are shown as waves, and the wave number of the sequence is represented by $k$. The formulas are as follows: 


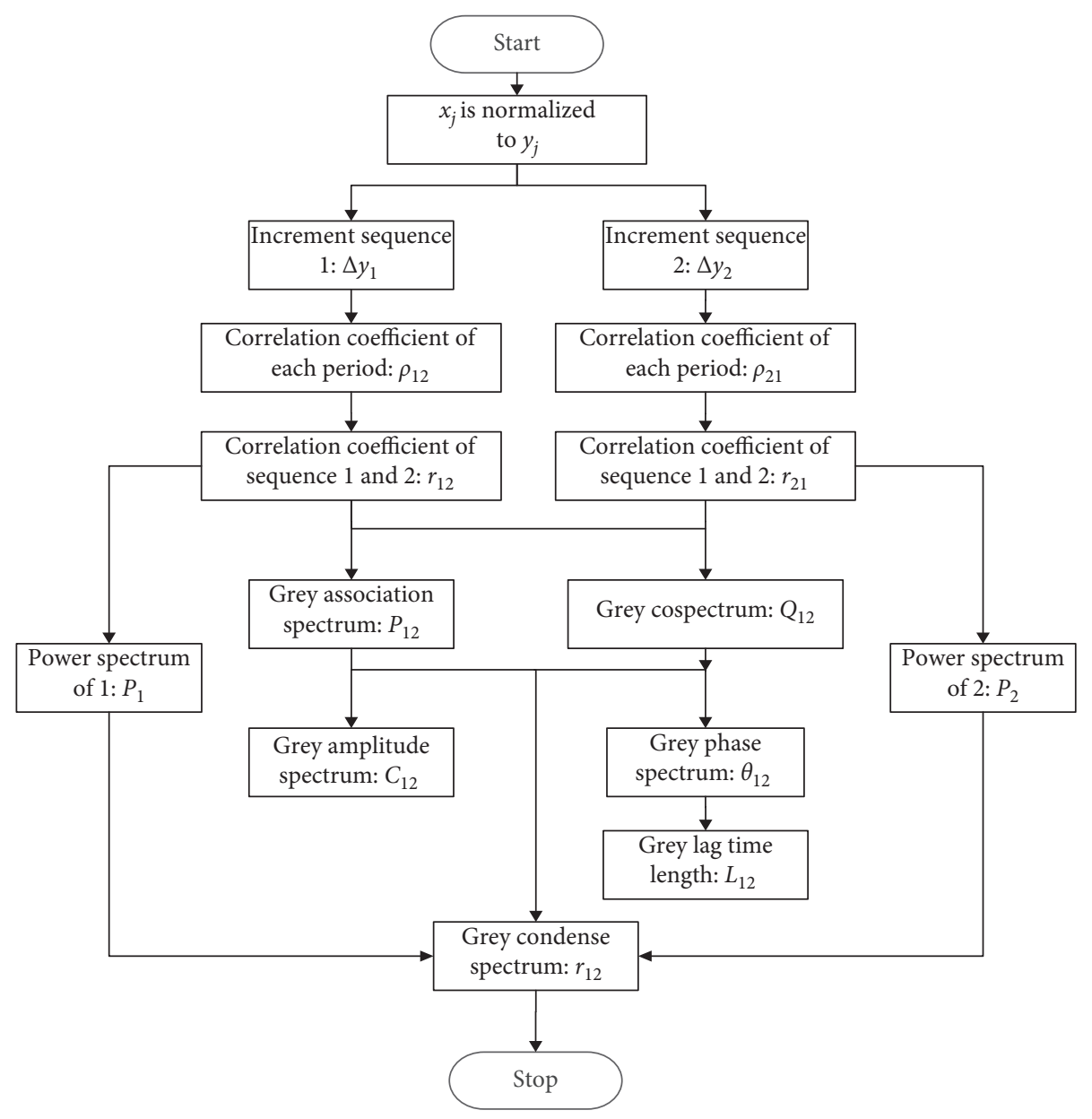

FIGURE 4: Flowchart of grey spectrum analysis.

$P_{12}(k)=\frac{1}{\Delta}\left\{r_{12}(0)+\sum_{\tau=1}^{\Delta-1}\left[r_{12}(\tau)+r_{21}(\tau)\right] \cos \frac{k \pi}{\Delta} \tau+r_{12}(\Delta) \cos (k \pi)\right\}$,

$Q_{12}(k)=\frac{1}{\Delta} \sum_{\tau-1}^{\Delta-1}\left[r_{12}(\tau)-r_{21}(\tau)\right] \sin \frac{k \pi}{\Delta} \tau, \quad k=0,1,2, \ldots, \Delta$.

Grey amplitude spectrum $C_{12}(k)$, grey phase spectrum $\theta_{12}(k)$, grey lag time length $L_{12}(k)$, and grey condense spectrum $r_{12}(k)$ are calculated using the grey association spectrum and grey cospectrum:

$$
\begin{aligned}
& C_{12}(k)=\sqrt{P_{12}^{2}(k)+Q_{12}^{2}(k)}, \\
& \theta_{12}(k)=\arctan \frac{Q_{12}(k)}{P_{12}(k)}, \\
& L_{12}(k)=\frac{\Delta \theta_{12}(k)}{\pi k}, \\
& r_{12}(k)=\operatorname{sgn}\left\{P_{1}(k) P_{2}(k)\right\} \frac{\min \left\{P_{12}^{2}(k)+Q_{12}^{2}(k),\left|P_{1}(k) P_{2}(k)\right|\right\}}{\max \left\{P_{12}^{2}(k)+Q_{12}^{2}(k),\left|P_{1}(k) P_{2}(k)\right|\right\}},
\end{aligned}
$$

where $-1 \leq r_{12}(k) \leq 1, P_{1}(k)$, and $P_{2}(k)$ are the grey association spectrum of two sequences of the $k$-th wave respectively, i.e., power spectrum.

Grey condense spectral $r_{12}(k)$ is different from the definition of condense spectral values in spectrum analysis. The paper expands the range of grey condense spectral value, a positive value here indicates a positive correlation, and a negative value does the opposite. $r_{12}(k)$ gets closer to -1 , and the negative correlation between $X_{1}$ and $X_{2}$ is stronger. Similarly, as $r_{12}(k)$ gets closer to 1 , the positive correlation between $X_{1}$ and $X_{2}$ is stronger. $r_{12}(k)=0$ expresses that $X_{1}$ and $X_{2}$ are not related.

As in spectral analysis theory, grey association spectrum reflects the same direction change components of the two sequences spectrum. Grey cospectrum represents reverse change component. Grey amplitude spectrum is composed of two components. The grey phase spectrum reflects phase difference of spectrum component of two sequences. The values range from $-\pi$ to $+\pi$, and $\pm \pi$ indicating the two grey spectrum components have exact opposite directions. In this, the grey association spectrum is zero, and the grey cospectrum is at its maximum. But if the grey phase spectrum is zero, the two grey spectrum components have 
TABLE 1: Grey association and cospectrum of AQI and housing price in Handan.

\begin{tabular}{|c|c|c|c|c|c|c|c|c|}
\hline Wave number & $P_{1}$ & $P_{2}$ & $P_{12}$ & $Q_{12}$ & $R_{12}$ & $H_{12}$ & $L_{12}$ & Period \\
\hline 1 & 0.0525 & 0.1734 & -0.0199 & 0.0104 & 0.0555 & -0.4821 & -1.5347 & 20.00 \\
\hline 2 & 0.0937 & 0.1105 & -0.0201 & -0.0333 & 0.1463 & 1.0274 & 1.6351 & 10.00 \\
\hline 3 & 0.1520 & 0.0506 & -0.0199 & 0.0216 & 0.1118 & -0.8258 & -0.8761 & 6.67 \\
\hline 4 & 0.1008 & 0.0848 & 0.0077 & 0.0023 & 0.0076 & 0.2901 & 0.2309 & 5.00 \\
\hline 5 & 0.1112 & 0.0847 & 0.0191 & -0.0154 & 0.0640 & -0.6802 & -0.4330 & 4.00 \\
\hline 6 & 0.0784 & 0.0625 & 0.0182 & -0.0190 & 0.1411 & -0.8088 & -0.4291 & 3.33 \\
\hline 7 & 0.0891 & 0.0873 & 0.0403 & -0.0123 & 0.2282 & -0.2969 & -0.1350 & 2.86 \\
\hline 8 & 0.1120 & 0.0471 & 0.0087 & -0.0173 & 0.0713 & -1.1054 & -0.4398 & 2.50 \\
\hline 9 & 0.0744 & 0.0546 & -0.0050 & -0.0018 & 0.0068 & 0.3426 & 0.1212 & 2.22 \\
\hline 10 & 0.0872 & 0.0571 & 0.0033 & 0.0000 & 0.0022 & 0.0000 & 0.0000 & 2.00 \\
\hline
\end{tabular}

$P_{1}$ is the AQI power spectrum, $P_{2}$ is the housing price power spectrum, $P_{12}$ is the grey association between AQI and housing price, $Q_{12}$ is the grey cospectrum, $R_{12}$ is the grey condense spectrum, $H_{12}$ is the grey phase spectrum, and $L_{12}$ is the grey lag time length.

exactly the same direction. The grey cospectrum is zero, and the grey association spectrum is at its maximum. There is a close relationship between the six kinds of grey spectrum.

\section{Case and Analysis}

We selected a city in southern Hebei Province, Handan. AQI and housing price were here analyzed from April 2015 to December 2018. The AQI data were collected from China's air quality online monitoring platform [19]. Housing price data is from reference [20]. AQI is the main sequence, and housing price is the secondary sequence. Grey spectrum theory is used to calculate six grey spectrum indicators in Handan. The results of the analysis of the relationship between AQI and housing price are shown in Table 1.

Extracting the main period of AQI change, in this paper, $\Delta=10$. AQI power spectrum of Handan is shown in Figure 5.

As shown in Table 1 and Figure 5, the three main periods in Handan AQI were extracted. The first period lasted 6.67 months; the second 2.5 months, and the third 4 months. The amplitudes of 1 st to 3 rd periods were 0.1520 , 0.1120 , and 0.1112 , respectively and tended to decline. The first period of Handan housing price lasted 20 months; the second 10 months; and the third 2.86 months. The amplitudes of 1 st to 3 rd periods were $0.1734,0.1105$, and 0.0873 , respectively. The results are shown in Table 2 . We can see that the first period has the largest amplitude and the third period has the smallest, indicating that housing price contributed the most to the change in AQI in the first period.

Grey association spectrum analysis was performed in Table 1 and Figure 6. AQI and housing price have different correlations in different frequency segments. Codirectional changes were observed lasting for 2.86 months, 4 months, and 3.33 months. As shown in Figure 7, grey cospectrum was used to reflect the reversed changes component lasting for 6.67 months, 20 months, and 5 months. As shown, the negative correlation period between AQI and housing price was longer than the positive period.

The phase angle of AQI before or after housing price was analyzed using the grey phase spectrum. As shown in

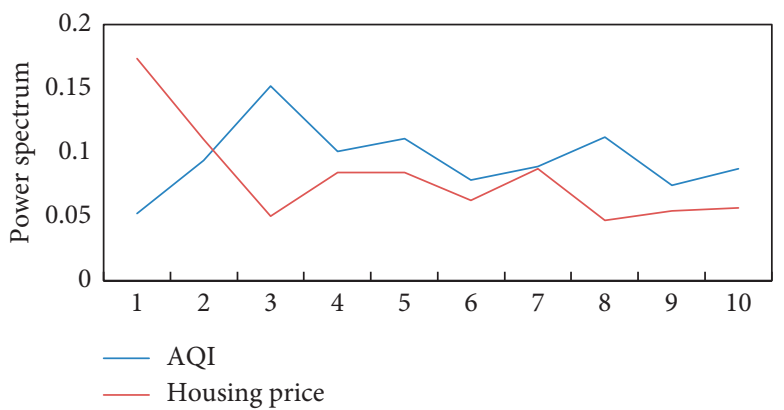

FIGURE 5: Spectrum of AQI and housing price power in Handan.

TABLE 2: Main period and amplitude of AQI and housing price in Handan.

\begin{tabular}{lcccc}
\hline \multirow{2}{*}{ Period } & \multicolumn{2}{c}{ AQI } & \multicolumn{2}{c}{ Housing price } \\
& Length & Amplitude & Length & Amplitude \\
\hline 1 & 6.67 & 0.1520 & 20 & 0.1734 \\
2 & 2.5 & 0.1120 & 10 & 0.1105 \\
3 & 4 & 0.1112 & 2.86 & 0.0873 \\
\hline
\end{tabular}

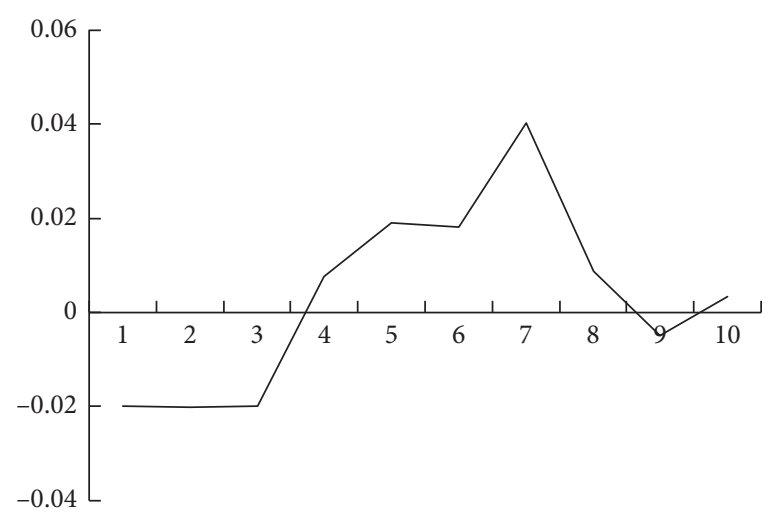

FIGURE 6: Grey association spectrum analysis of AQI and housing price.

Table 1 and Figure 8, the impact of housing price on AQI is both ahead and behind. The maximum values were $1.0274 \mathrm{rad}$ and $1.1054 \mathrm{rad}$. Next, how long each value 


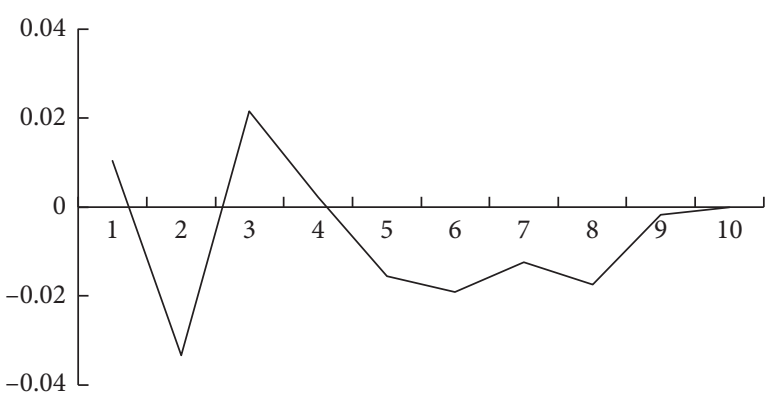

FIGURE 7: Grey cospectrum of AQI and housing price.

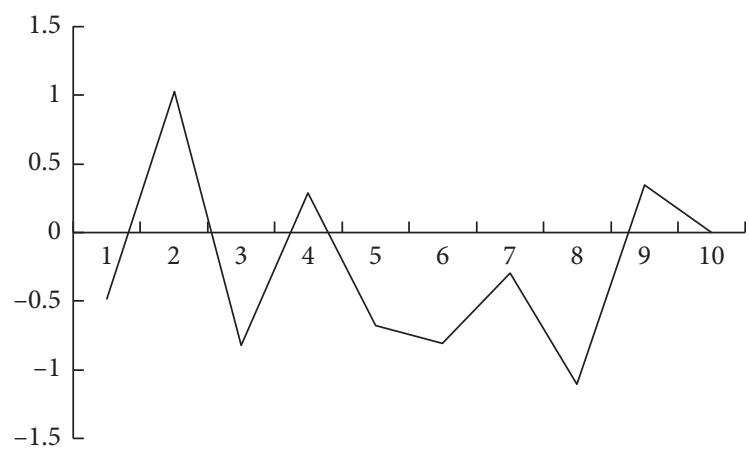

FIgURE 8: Grey phase spectrum of AQI and housing price.

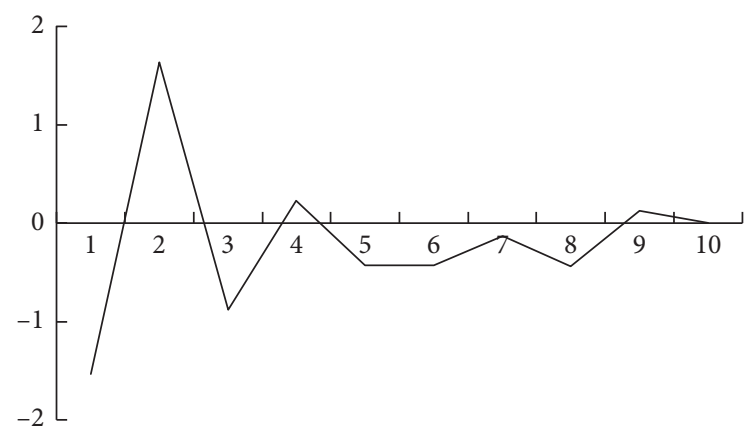

FIgure 9: Grey lag time length of AQI and housing price.

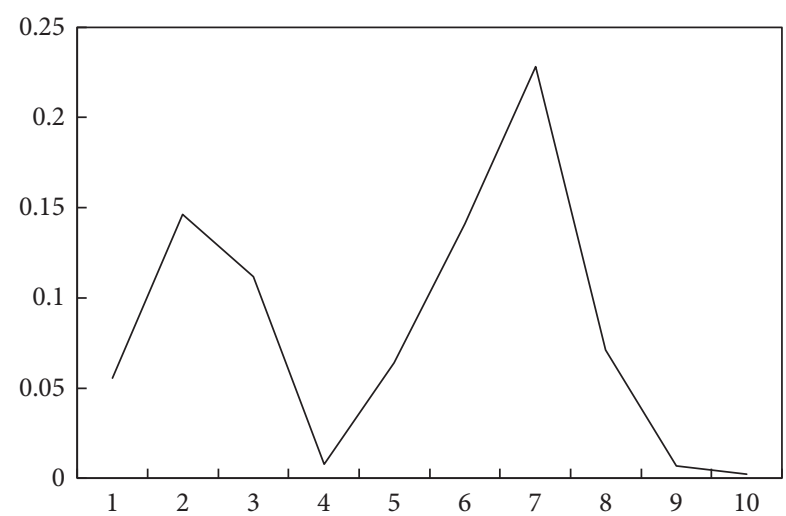

FIGURE 10: Grey condense spectrum of AQI and housing price.

remained behind or ahead was found using grey lag time length. As shown in Table 1 and Figure 9, the lag time between AQI and housing price was -1.5347 to 1.6351 months, the maximum time housing price remained ahead of AQI was 1.6351 months, and the maximum time it lagged behind was 1.5347 months.

The calculated results of grey condense spectrum are shown in Figure 10 and Table 1. The highest grey condense spectrum values were 2.86 months, 10 months, and 3.33 months and the amplitude of these were $0.0403,-0.0201$, and 0.0182 . These results show that AQI and housing price fluctuated closely across a 2 - to 10 -month period.

\section{Conclusions and Future Work}

The main periods of AQI and housing price are extracted, and they range from 2 to 20 months. The amplitudes of AQI and housing price are both measured for the first period. This shows that AQI and housing price changed the most during the first period. Under the control of government policies, housing prices are gradually stabilizing and the air quality tends to improve. The negative correlation between AQI and housing price is obvious. Due to the strict implementation of environmental protection policy, housing construction cycles have lengthened. Because of environmental problems, work stoppages are common. In addition to the abovementioned reasons, there are further reasons for air pollution. First, geographic location determines the degree of air circulation. The smog in cities on the plains does not last long. Cities like Handan are located in a mountainous area where the haze does not easily diffuse. Second, building density affects air circulation. The area of urbanization continues to expand, and more and more people have come to live in downtown areas, which further worsen air pollution. Third, a large population and limited land incentivizes the construction of taller buildings, which also affects the timely circulation of air.

The empirical results given here provide a reference that the government may use to prevent haze. The relationship between AQI and housing price in Handan is only analyzed using grey spectrum theory. Whether there is a consistent connection in other areas has not been verified and needs further research.

\section{Data Availability}

All data used to support the findings of this study are included within the article.

\section{Conflicts of Interest}

All authors declare that they have no conflicts of interest.

\section{Acknowledgments}

The relevant research studies in this paper are supported by the National Natural Science Foundation of China (nos. 71871084 and 71401051), the Excellent Young Scientist Foundation of Hebei Education Department (no. SLRC2019001), and the project of high-level talent in Hebei Province. 


\section{References}

[1] H. M. Long and W. Guo, "Analysis on the relationship between housing price and land price in China by VAR model," Mathematics in Economics, vol. 26, no. 2, pp. 52-58, 2009.

[2] C. Choi, H. Jung, and L. Su, "Population structure and housing prices: evidence from Chinese provincial panel data," Emerging Markets Finance and Trade, vol. 55, no. 1, pp. 29-38, 2019.

[3] C. Jin and M. J. Choi, "The causal structure of land finance, commercial housing, and social housing in China," International Journal of Urban Sciences, vol. 23, no. 6, pp. 286-299, 2019.

[4] Z. Du and L. Zhang, "Home-purchase restriction, property tax and housing price in China: a counterfactual analysis," Journal of Econometrics, vol. 188, no. 2, pp. 558-568, 2015.

[5] R. Liu and L. Liu, "Predicting housing price in China based on long short-term memory incorporating modified genetic algorithm," Soft Computing, 2019.

[6] R. Samson, R. D. Grote, C. Calfapietra et al., Urban Trees and Their Relation to Air Pollution, Springer International Publish AG, Basel, Switzerland, 2017.

[7] M. Mao, H. Liu, and X. U. Honghui, "The key factor research of haze with the combined application of the multi element data," Acta Scientiae Circumstantiae, vol. 33, no. 3, pp. 806813, 2013.

[8] X. Li, W. Zheng, L. Yin, Z. Yin, L. Song, and X. Tian, "Influence of social-economic activities on air pollutants in Beijing, China," Open Geosciences, vol. 9, no. 1, pp. 314-321, 2017.

[9] M. Azimi, F. Feng, and C. Zhou, "Air pollution inequality and health inequality in China: an empirical study," Environmental Science and Pollution Research, vol. 26, no. 12, pp. 11962-11974, 2019.

[10] J. He, S. Gong, Y. Yu et al., "Air pollution characteristics and their relation to meteorological conditions during 2014-2015 in major Chinese cities," Environmental Pollution, vol. 223, pp. 484-496, 2017.

[11] C. Sun, J. Zhang, Y. Guo et al., "Outdoor air pollution in relation to sick building syndrome (SBS) symptoms among residents in Shanghai, China," Energy and Buildings, vol. 174, pp. 68-76, 2018.

[12] L. Wu, S. Liu, L. Yao, and S. Yan, "The effect of sample size on the grey system model," Applied Mathematical Modelling, vol. 37, no. 9, pp. 6577-6583, 2013.

[13] T.-Y. Pai, K. Hanaki, and R.-J. Chiou, "Forecasting hourly roadside particulate matter in Taipei county of Taiwan based on first-order and one-variable grey model," CLEAN-Soil, Air, Water, vol. 41, no. 8, pp. 737-742, 2013.

[14] L. Wu, N. Li, and Y. Yang, "Prediction of air quality indicators for the Beijing-Tianjin-Hebei region," Journal of Cleaner Production, vol. 196, pp. 682-687, 2018.

[15] B. Zhu, L. Yuan, and S. Ye, "Examining the multi-timescales of European carbon market with grey relational analysis and empirical mode decomposition," Physica A: Statistical Mechanics and Its Applications, vol. 517, pp. 392-399, 2019.

[16] S. Liu, Y. Yang, and L. Wu, Grey System Theory and Its Application, Science Press, Beijing, China, 2014.

[17] Q. Huang and X. Zhao, Theory and Method of River Runoff Time Series Analysis and Prediction, Yellow River Water Conservancy Press, Zhengzhou, China, 2008.

[18] J. Wang, "Time series periodic analysis based on energy association degree," System Engineering Theory Practice, vol. 9, pp. 83-85, 1998.
[19] China Air Quality Online Monitoring Platform, https://www. aqistudy.cn/historydata/daydata.php?city $=\% \mathrm{E} 9 \% 82 \% \mathrm{AF} \%$ E9\%83\%B8\&month=201.

[20] Anjuke, https://www.anjuke.com/fangjia/. 


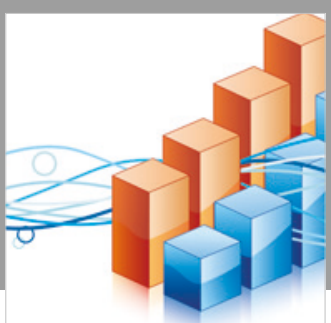

Advances in

Operations Research

\section{-n-m}
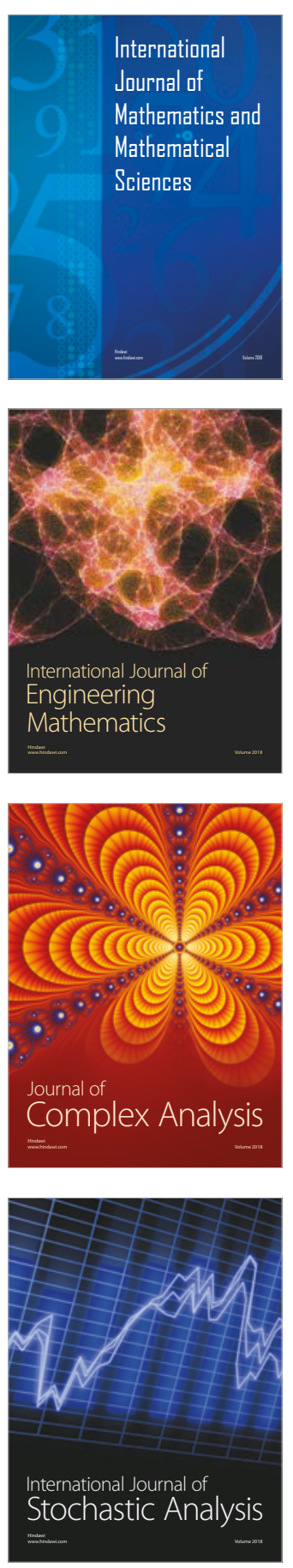
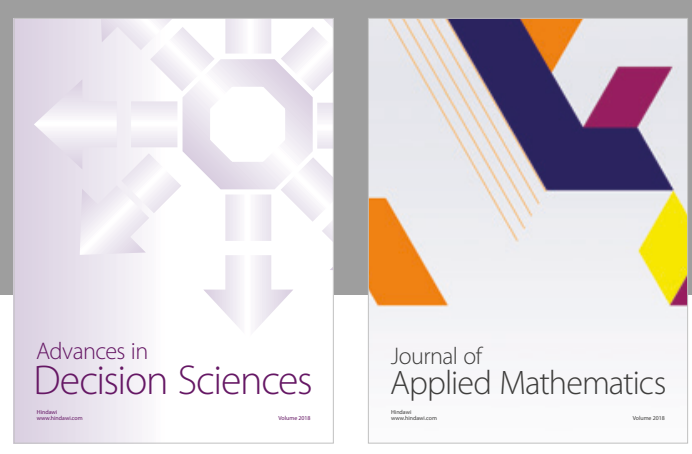

Journal of

Applied Mathematics
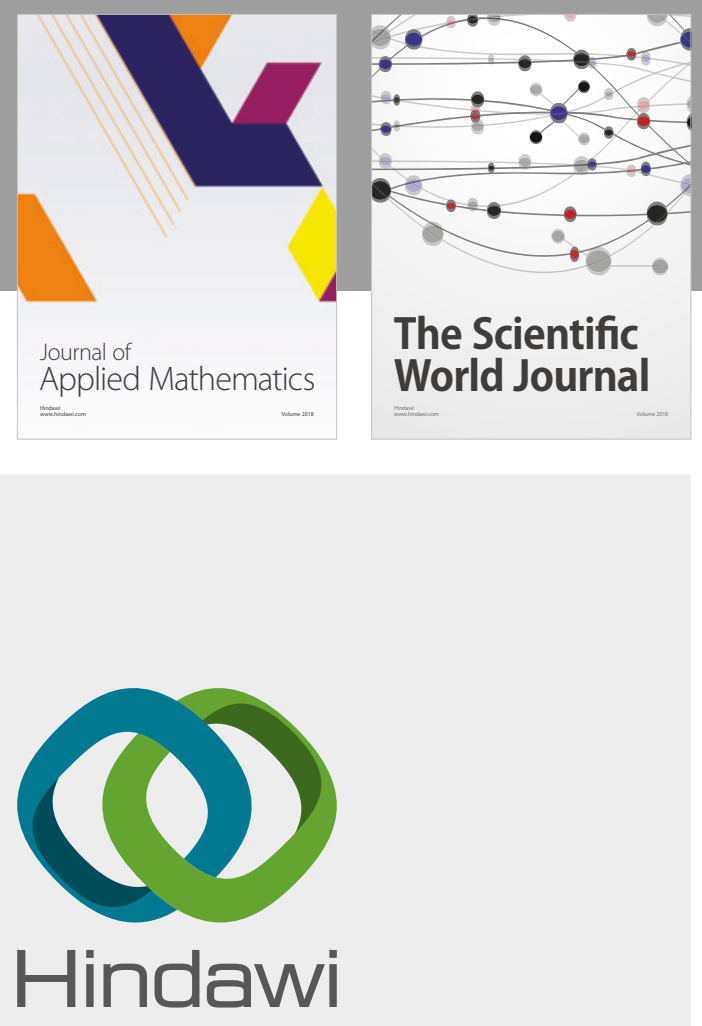

Submit your manuscripts at

www.hindawi.com

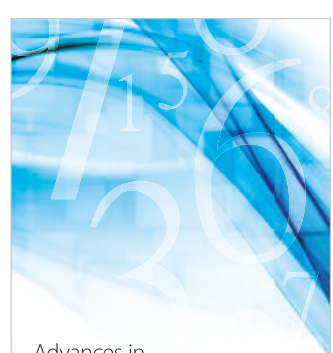

Advances in
Numerical Analysis
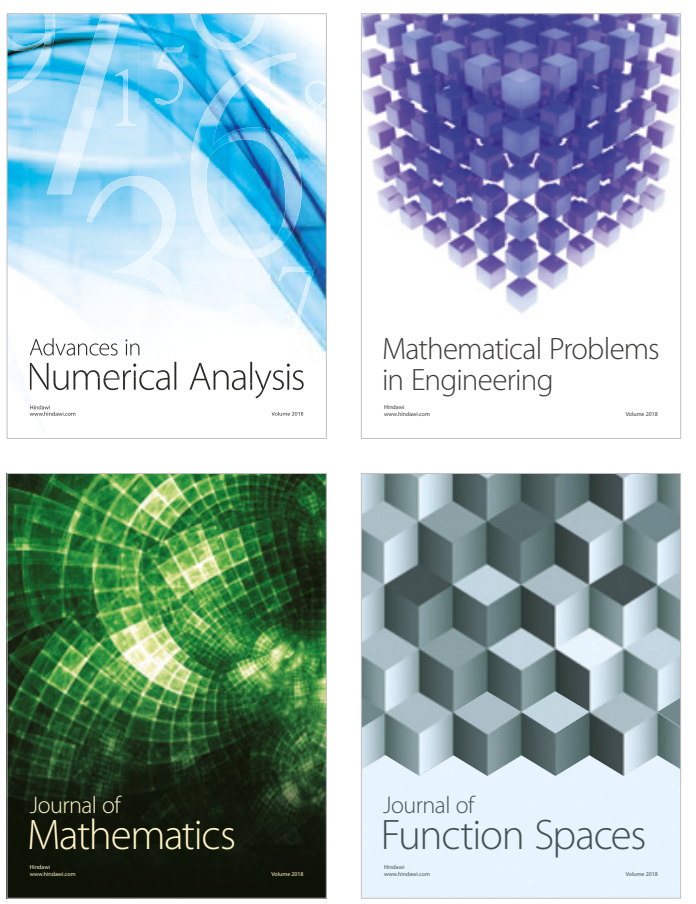

Mathematical Problems in Engineering

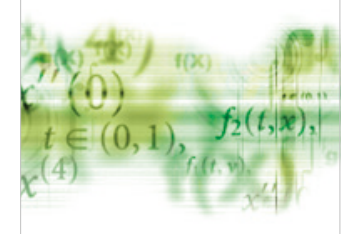

International Journal of

Differential Equations

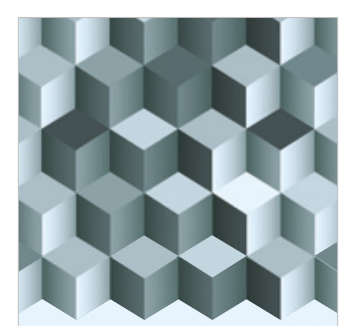

Journal of

Function Spaces
The Scientific

World Journal

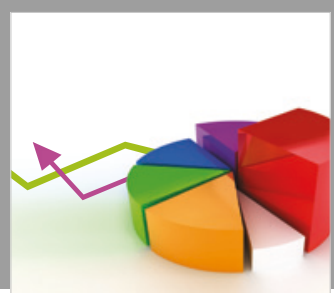

Journal of

Probability and Statistics
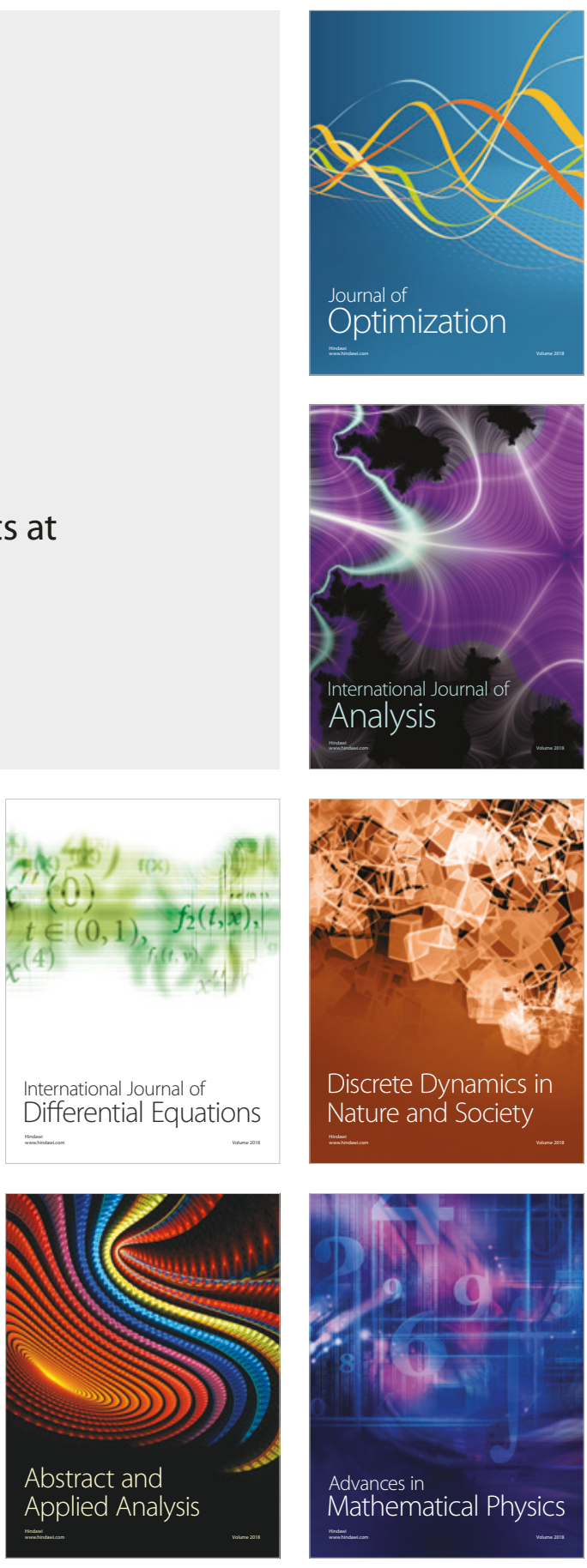